\title{
Ectrodactyly-ectodermal dysplasia-cleft lip/palate syndrome: a rare entity
}

\author{
Samrat Sabhlok ${ }^{1}$, Sobhan Mishra², Ramanupam Tripathy ${ }^{2}$, Deepthi Mony ${ }^{3}$ \\ ${ }^{1}$ Department of Oral and Maxillofacial Surgery, Dr. D. Y. Patil Dental College and Hospital, Pune 411018, Maharashtra, India. \\ ${ }^{2}$ Department of Oral and Maxillofacial Surgery, Institute of Dental Sciences, Bhubaneshwar, Odisha 751003, India. \\ ${ }^{3}$ Consultant Oral and Maxillofacial Surgeon, Navi Mumbai 400706, Maharashtra, India.
}

Address for correspondence: Dr. Samrat Sabhlok, Department of Oral and Maxillofacial Surgery, Dr. D. Y. Patil Dental College and Hospital, Pune 411018, Maharashtra, India. E-mail: samratsabhlok@yahoo.com

\begin{abstract}
Ectrodactyly-ectodermic dysplasia-cleft lip/palate (EEC) syndrome is a rare congenital anomaly of inherited origin and varying clinical features. This syndrome has three main symptoms, which display variable expression and penetrance. The management of this syndrome is challenging, with few reports in the medical literature. We present a case of a 22-year-old boy with EEC syndrome and offer insight into current knowledge about this syndrome.
\end{abstract}

Key words:

Cleft lip and palate, ectodermal dysplasia, ectrodactyly

\section{INTRODUCTION}

Ectrodactyly-ectodermic dysplasia-cleft lip/palate (EEC) syndrome applies to a triad of inherited congenital anomalies including ectrodactyly (lobster claw deformities of the hands/feet), ectodermic dysplasia (ED) (fine, short hair, absent eyebrows and eyelashes, dystrophic nails, diffuse scaling and palmoplantar keratoderma) and cleft lip with or without cleft palate. ${ }^{[1]}$ The syndrome was first documented in a tribe from German Guyana in South America, in 1770 while Eckholdt and Martens described the syndrome for the 1 st time in 1804. ${ }^{[2]}$ In 1936, Cockayne described a pedigree of two generations with split hands and feet, cleft lip and palate and dacryocystitis. Subsequently, Walker and Clodius described three pedigrees with complete unilateral or bilateral clefts of the primary and secondary palate associated with lobster claw hands and feet and malfunction of the lacrimal system. ${ }^{[3]}$ In 1970, Rudiger and associates described the rare combination of ectrodactyly (lobster claw deformity), ED

\begin{tabular}{|l|l|}
\hline \multicolumn{2}{|c|}{ Access this article online } \\
\hline Quick Response Code: & Website: \\
\hline & www.parjournal.net \\
\cline { 2 - 3 } & \\
\hline & \\
\hline
\end{tabular}

(with atresia of the nasolacrimal duct) and cleft lip with or without cleft palate, terming it EEC syndrome. ${ }^{[4]}$

It is a rare syndrome, with the frequency of ectrodactyly at 1.5/100,000 live births and 1/100,000 live births for cleft palate with or without a cleft lip. ${ }^{[5]}$ The occurrence of all three disorders in one, that is, ectrodactyly, ectodermal dysplasia, and cleft lip/palate, is reported to be approximately $1.5 / 100$ million. ${ }^{[6]}$

EEC syndrome shows an autosomal dominant inheritance pattern with variable expressivity and incomplete penetrance, although autosomal recessive inheritance has also been reported. ${ }^{[7]}$

The responsible gene has been identified as the p63 gene, which is essential for limb formation and epidermal morphogenesis including adnexa (teeth, hair, mammary and prostate glands. $)^{[8]}$ The mutation of this gene accounts for most, if not all, cases of the classic EEC syndrome. ${ }^{[6]}$

This is an open access article distributed under the terms of the Creative Commons Attribution-NonCommercial-ShareAlike 3.0 License, which allows others to remix, tweak, and build upon the work non-commercially, as long as the author is credited and the new creations are licensed under the identical terms.

For reprints contact: reprints@medknow.com

How to cite this article: Sabhlok S, Mishra S, Tripathy R, Mony D. Ectrodactyly-ectodermal dysplasia-cleft lip/palate syndrome: a rare entity. Plast Aesthet Res 2015;2:290-3.

Received: 01-04-2015; Accepted: 10-07-2015 
There are a wide array of features noted in association with the syndrome, including genitourinary defects, mental retardation, midface hypoplasia, auricular anomalies, hypopigmentation of the skin, an increased number of nevocellular nevi, ${ }^{[4]}$ conductive hearing loss, ${ }^{[3]}$ nipple abnormalities, lumbar lordosis, short stature, ${ }^{[9]}$ glaucoma, and blindness. ${ }^{\mid 10]}$

The cosmetic aspects of EEC can have a tremendous impact on quality of life. The facial and limb differences can be socially isolating and physically challenging for both children and adults.

There are a few cases of EEC syndrome reported in the literature, with variable presentation. Here, we offer an insight into the diagnosis and management of EEC syndrome through the presentation of a case.

\section{CASE REPORT}

A 22-year-old man presented to our unit with a chief complaint of cleft lip and cleft palate. There was no family history of any such deformity.

On physical examination, the patient had a wide left unilateral complete cleft lip and palate [Figure 1]. Clinical features show shortening of the philtral height, shortened columella, the flattened alar dome on the cleft side and alar rim distortion, which reduced the apparent height of the columella.

The examination of the upper extremities was remarkable for ectrodactyly. The right hand showed clefting between the second and fourth digits with the absence of the third digit. The left hand showed clefting in the same region with a deformity between the second and fourth digits and absence of the third digit [Figure 2]. The lower extremities were remarkable for ectrodactyly of the right foot with clefting present between the great toe and third digit of the right foot and absence of the second digit [Figure 3].

The scalp, hair and eyebrows were light, short, thin, brittle and kinky. There was no dermatitis of the scalp. The eyebrows were especially sparse in their lateral halves. The patient's skin was significantly thickened and dry, especially on the extremities, with ridged and brittle toenails. The parents reported that he seldom sweated. The evaluation of the patient's psychomotor development showed moderate retardation. The speech disorder was attributed to both his anatomical lip and palate impairment and psychomotor retardation. The ophthalmological examination revealed no abnormality and no epiphora. Audiometric analysis showed no conduction blockade.

The intraoral examination was notable for a complete cleft palate. There were multiple carious and missing teeth. An orthopantomograph revealed a wide alveolar cleft in the left maxilla in the region of the left incisor and canine. Radiographic examination of the hands revealed a fusion of the metacarpals and phalanges of the first and second digits and a deformity of the third metacarpal of the right

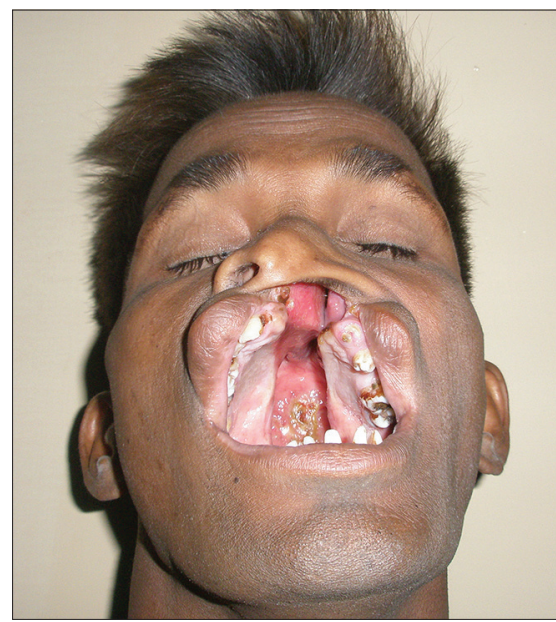

Figure 1: Wide left unilateral complete cleft lip and palate

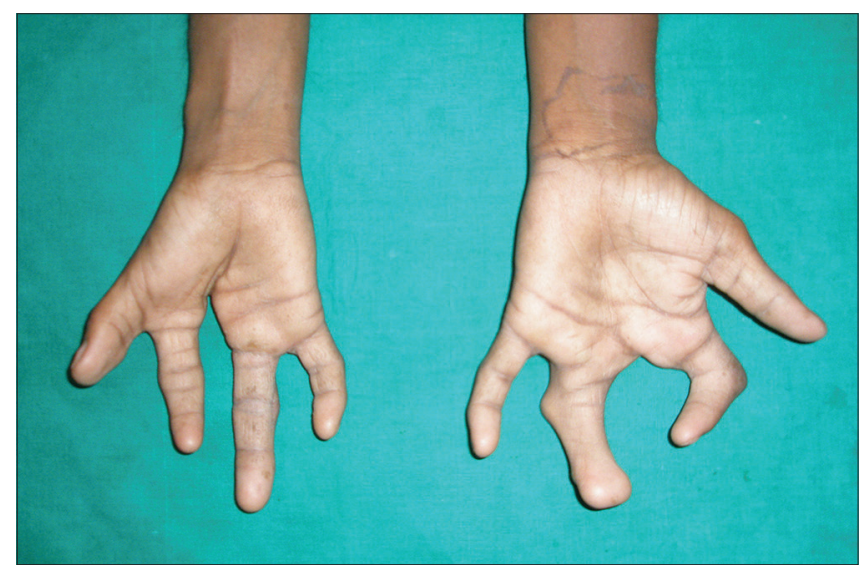

Figure 2: Upper extremities showing ectrodactyly

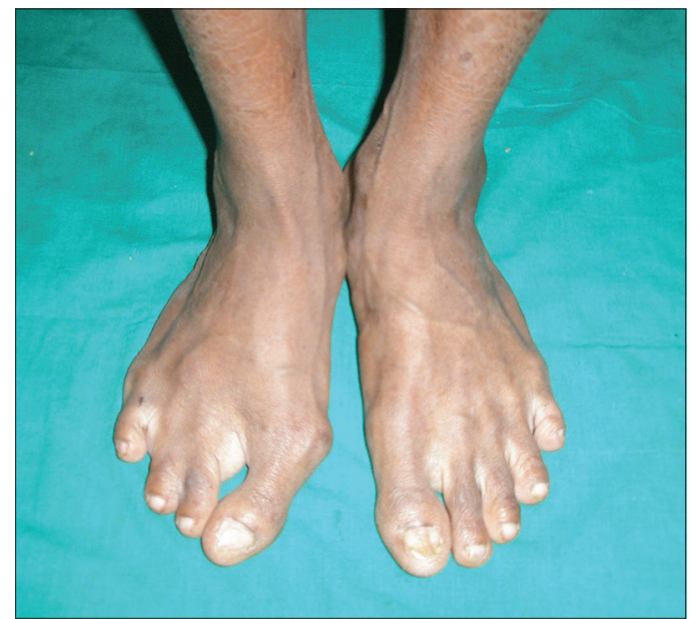

Figure 3: Clefting present in between the great toe and the third digit of the right foot

hand. The left hand revealed a deformity of the phalanges of the second digit, with fusion and deformity of the third and fourth digits [Figure 4]. The right foot shows a deformity of the second metatarsal and the absence of phalanges of the second digit [Figure 5].

The patient was taken to the operating room for repair of the cleft lip and palate under general anesthesia. The cleft lip was repaired with use of the Millard incision, and the palate was repaired using the Bardach two flap 
palatoplasty technique. The patient reported for follow-up on a regular basis for a period of six months [Figure 6]. The hypernasal quality of the voice did not improve following palatoplasty. Although speech therapy was prescribed, the patient did not return for treatment.

\section{DISCUSSION}

EEC syndrome is a rare autosomal dominant multiple congenital anomaly syndromes with variable expression. Disease-causing mutations have been identified in the p63

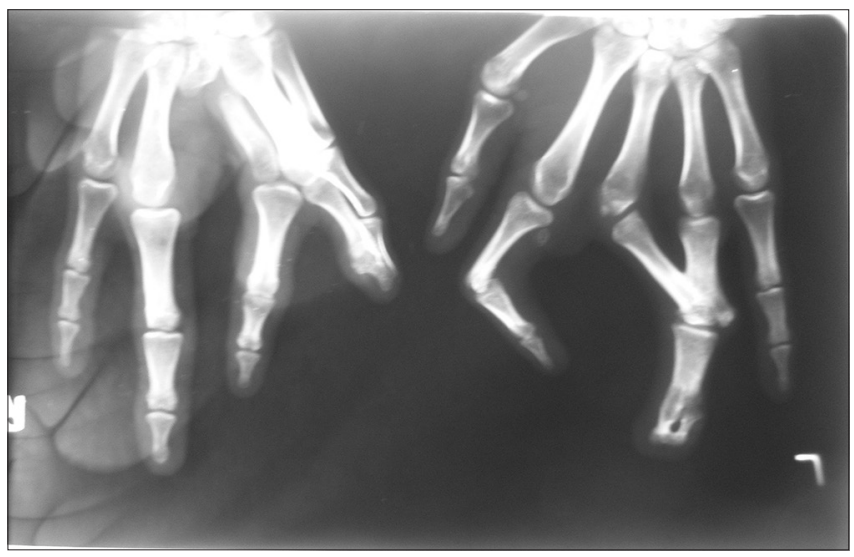

Figure 4: Radiograph of upper extremities showing ectrodactyly

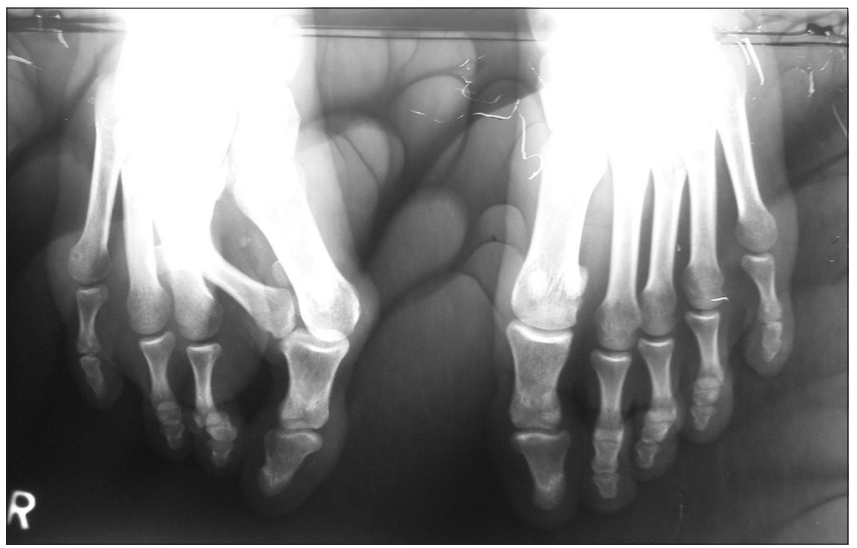

Figure 5: Radiograph of lower extremity showing deformity of the second metatarsal and the absence of phalanges of the second digit

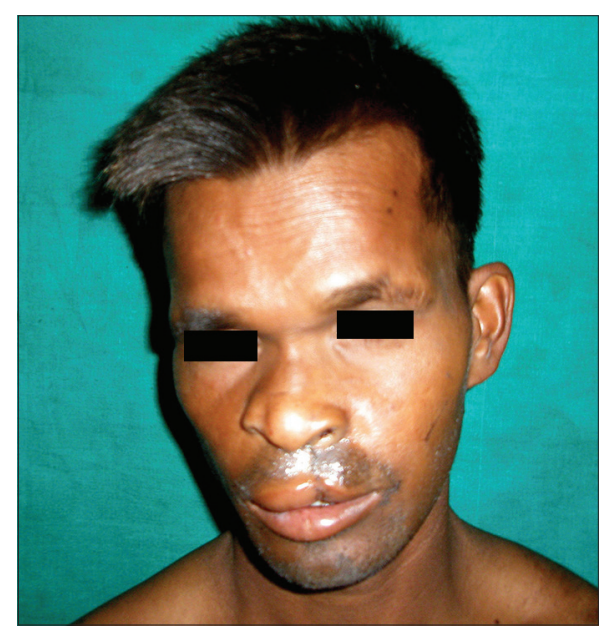

Figure 6: Six months postoperative gene, a homolog of the p53 tumor suppressor gene. The p63 produces a protein, which is essential for ectodermal development. The mutation is thought to affect $p 63$ binding to DNA, resulting in abnormal ectodermal development. ${ }^{[1,12]}$ The $p 63$ is expressed in the ectodermal surfaces of the limb buds. Limb truncations are due to a failure to maintain the apical ectodermal ridge, a stratified epithelium essential for limb development. The p63 is critical for maintaining the progenitor-cell populations necessary for epithelial development and morphogenesis. ${ }^{[13]}$

There are three types of EEC syndrome, with gene loci identified as follows:

- EEC syndrome type 1 (Mendelian Inheritance in Man (MIM) 129900)-7q11.2-q21.3;

- EEC syndrome type 2 (MIM 602077)-chromosome 19;

- EEC syndrome type 3 (MIM 604292)-3q27.

Different combinations of ectodermal dysplasia, orofacial clefting and limb malformation are seen in five different syndromes: EEC syndrome (most common, OMIM 604292), ankyloblepharon-ectodermal defect-cleft lip/palate syndrome (AEC, OMIM 106260), limb mammary syndrome (LMS, OMIM 603543), acro-dermato-ungual-lacrimal-tooth syndrome (adult, OMIM 103285), and Rapp-Hodgkin syndrome (RHS, OMIM 129400).. ${ }^{[14]}$ The term ectrodactyly originates from the Greek "ektroma" (abortion) and "daktylos" (finger). In 1829, von Walter described the characteristic crab foot, which Cruveilhier later coined the "lobster foot". ${ }^{[1]}$ Ectrodactyly, cleft foot, lobster foot and crab-claw foot are synonyms expressing the absence of, to a greater or lesser degree, the central digits and metacarpals or metatarsals of the feet and hands, respectively. The first and fifth rays are generally present, although sometimes the first is hypertrophied. The usual presentation involves the hands and feet bilaterally. ${ }^{[1]}$ Our case demonstrated ectrodactyly of both hands and the right foot. According to Blauth and Borisch ${ }^{[15]}$ six level radiographic classification of cleft feet, the right foot is Grade II, as there are five metatarsals, which are partially hypoplastic or synostotic with other metatarsals or phalanges. The second or third ray is always affected, and at least one toe is absent.

ED syndrome requires involvement from the birth of hair, skin, teeth or nails without progression of the condition. The signs of ED were seen in the present case as the hair was brittle but not sparse. The anodontia noted in the maxillary arch may have been secondary to the cleft palate, however, the anodontia of the mandibular arch could be attributed to ED. The toenails were ridged, thick and brittle. The patient's skin was pigmented and prone to rashes.

Making a diagnosis of ED is challenging as any ectodermal derivative may be involved in varying degrees, and other systems may also be affected. To circumvent this problem, Freire-Maia and Pinheiro designed a classification system, which contains over 100 clinically distinct conditions. ${ }^{[9,15,16]}$ Freire-Maia and Pinheiro based their definition on four "classical signs" associated with ED: trichodysplasia, 
dental defects, onychodysplasia and dyshidrosis. Group A includes those disorders with signs affecting at least two of the classical structures: (1) hair, (2) teeth, (3) nails, and (4) sweat glands. Group B includes disorders involving one of the classical signs associated with another ectodermal sign. "Pure" ED is characterized by only ectodermal signs while ED syndrome combines ectodermal signs and other malformations. ${ }^{[17]}$

Several clinical syndromes are characterized by ED in association with clefting of the lip and/or palate. The three most commonly recognized are (1) EEC syndrome (ED, ectrodactyly, cleft lip/palate); (2) Rapp-Hodgkin syndrome with ED, cleft lip/palate, and midfacial hypoplasia; and (3) Hay-Wells or AEC syndrome. ${ }^{[18]}$

Clinical expression of the components of this syndrome is very diverse. The cases of EEC syndrome without cleft lip or cleft palate have been reported. ${ }^{[19]}$ The patient presented in the above report showed unilateral complete cleft lip and palate, which was the primary motivation for seeking treatment. The frequency of presentation of the different manifestations is as follows: ectodermal dysplasia (10-100\%), lacrimal duct alterations (70-96.5\%), ectrodactyly (78-88\%), cleft lip/palate (58-88\%), urogenital alterations (15-55\%), deafness (8-28\%) and mental retardation (1-16\%). ${ }^{[20-22]}$

EEC syndrome can be diagnosed prenatally by ultrasound, which detects the structural abnormalities associated with the syndrome including cleft lip, cleft palate, kidney abnormalities and limb abnormalities. Prenatal DNA testing can be done by chorionic villi sampling or amniocentesis. Mutation of the $p 63$ gene is diagnostic for EEC syndrome.

Although there is no specific cure for EEC syndrome, there are many treatments available for the various symptoms. Our patient's main concern was his wide cleft lip and palate for which he underwent surgical repair. In most patients, the cleft lip and palate are surgically repaired early in life to address the issues with nutrition and speech. However, many patients appear to adapt well to the limb deformities of EEC syndrome. From a dental viewpoint, the dentition should be preserved as long as possible by restoring the teeth. Saliva ${ }^{[23]}$ substitutes can be used in cases of severe xerostomia.

The above patient was not extremely concerned about the malformation of his hands or feet. The Grade II ectrodactyly of his feet did not affect his gait or the fit of his shoes, but gait problems are seen in Grades III or greater. Treatment of the foot malformation brings the size of the foot into the normal range, fills the cleft, corrects the secondary deformities and maintains good function. ${ }^{[1]}$

In conclusion, the ideal treatment plan includes early diagnosis and a multidisciplinary approach. An endeavor should be made to establish a protocol for the treatment of EEC syndrome to minimize progression of the deformities.

\section{Financial support and sponsorship}

Nil.

\section{Conflicts of interest}

There are no conflicts of interest.

\section{REFERENCES}

I. Pẽna DA, Nova AM, Pẽna JA, Ruiz SH. Cleft foot and ectrodactyly-ectodermic dysplasia-cleft lip/palate syndrome review of the literature and report of two new cases. Foot 2004; 14:221-6.

2. South AP, Ashton GH, Willoughby C, Ellis IH, Bleck O, Hamada T, Mannion G, Wessagowit V, Hashimoto T, Eady RA, McGrath JA. EEC (Ectrodactyly, 3. 3. Ectodermal dysplasia, Clefting) syndrome: heterozygous mutation in the p63 gene $(\mathrm{R} 279 \mathrm{H})$ and DNA-based prenatal diagnosis. Br J Dermatol 2002; 146:216-20.

3. Robinson GC, Wildervanek LS, Chiang TP. Ectrodactyly, ectodermal dysplasia, and cleft lip-palate syndrome. Its association with conductive hearing loss. J Pediatr 1973;82:107-9.

4. Rüdiger RA, Haase W, Passarge E. Association of ectrodactyly, ectodermal dysplasia, and cleft lip-palate. Am J Dis Child 1970;120:160-3.

5. Marwaha M, Nanda KD. Ectrodactyly, ectodermal dysplasia, cleft lip, and palate (EEC syndrome). Contemp Clin Dent 2012;3:205-20.

6. Oğur G, Yüksel M. Association of syndactyly, ectodermal dysplasia, and cleft lip and palate: report of two sibs from Turkey. J Med Genet 1988;25:37-40.

7. Brunner HG, Hamel BC, van Bokhoven $H$. The $p 63$ gene in EEC and other syndromes. J Med Genet 2002;39:377-8I.

8. Balci S, Engiz O, Okten G, Sipahier M, Gursu G, Kandemir B. A 19-year follow-up of a patient with type 3 ectrodactyly-ectodermal dysplasia-clefting syndrome who developed non-Hodgkin lymphoma. Oral Surg Oral Med Oral Pathol Oral Radiol Endod 2009; 108:e9l-5.

9. Soekarman D, Fryns JP. Hypohidrotic ectodermal dysplasia, central nervous system malformation, and distinct facial features: confirmation of a distinct entity? J Med Genet 1992;30:245-7.

10. Rosenberg JB, Butrus S, Bazemore MG. Ectrodactyly-ectodermal dysplasia-clefting syndrome causing blindness in a child. JAAPOS 20II;15:80-2.

II. Celli J, Duijf P, Hamel BC, Bamshad M, Kramer B, Smits AP, Newbury-Ecob R, Hennekam RC, van Buggenhout G, van Haeringen A, Woods CG, van Essen AJ, de Waal R, Vriend G, Haber DA, Yang A, McKeon F, Brunner HG, van Bokhoven $\mathrm{H}$. Heterozygous germline mutations in the $\mathrm{p} 53$ homolog $\mathrm{p} 63$ are the cause of EEC syndrome. Cell 1999;99:143-53.

12. Levrero M, De Laurenzi V, Costanzo A, Gong J, Wang JY, Melino G. The p53/ p63/p73 family of transcription factors: overlapping and distinct functions. J Cell Sci 2000; I 13:166I-70.

13. Yang A, Schweitzer R, Sun D, Kaghad M, Walker N, Bronson RT, Tabin C, Sharpe A, Caput D, Crum C, McKeon F. p63 is essential for regenerative proliferation in limb, craniofacial and epithelial development. Nature 1999;398:7|4-8.

14. Agrawal A, Agrawal R, Singh R, Agrawal R, Agrawal S. Lobster claw deformity. Indian J Dent Res 2014;25:243-7.

15. Blauth W, Borisch NC. Cleft feet. Proposals for a new classification based on roentgenographic morphology. Clin Orthop Relat Res 1990;258:41-8.

16. Freire-Maia N, Pinheiro M. Ectodermal Dysplasias: a Clinical and Genetic Study. New York: Alan R Liss; 1984. p. 172-3.

17. Freire-Maia N. Ectodermal dysplasias. Hum Hered 1971;21:309-I2.

18. Fosko SW, Stenn KS, Bolognia JL. Ectodermal dysplasias associated with clefting: significance of scalp dermatitis. J Am Acad Dermatol 1992;27:249-56.

19. Thakkar S, Marfatia Y. EEC syndrome sans clefting: variable clinical presentations in a family. Indian J Dermatol Venereol Leprol 2007;73:46-8.

20. Dipak NK, Sheikh S, Srinivasan A. EEC (Ectrodactyly-ectodermal dysplasia clefting) syndrome in a Newly Born Baby. Int J Intgr Med Sci 2015;2:87-9.

21. Rodini ES, Richieri-Costa A. EEC Syndrome: report on 20 new patients, clinical and genetic considerations. Am J Med Genet 1990;37:42-53.

22. Koul M, Dwivedi R, Upadhyay V. Ectrodactyly-ectodermal dysplasia clefting syndrome (EEC syndrome). J Oral Biol Craniofac Res 2014;4:135-9.

23. Dhar RS, Bora A. Ectrodactyly-ectodermal dysplasia-cleft lip and palate syndrome. J Indian Soc Pedod Prev Dent 2014;32:346-9. 